\title{
Erratum to: Two-dimensional proteomic analysis of honeybee, Apis mellifera, winter worker hemolymph
}

\author{
Tomas ERBAn ${ }^{1}$, Petr L. Jedelsky ${ }^{2,3,4}$, Dalibor Titera ${ }^{5}$ \\ ${ }^{1}$ Department of Pest Control of Stored Products and Food Safety, Laboratory of Proteomics, Crop Research \\ Institute, Drnovska 507/73, Prague 6-Ruzyne CZ16106, Czech Republic \\ ${ }^{2}$ Department of Parasitology, Faculty of Science, Charles University in Prague, Prague, Czech Republic \\ ${ }^{3}$ Laboratory of Mass Spectrometry, Faculty of Science, Charles University in Prague, Prague, Czech Republic \\ ${ }^{4}$ Department of Cell Biology, Faculty of Science, Charles University in Prague, Prague, Czech Republic \\ ${ }^{5}$ Bee Research Institute at Dol, Libcice nad Vltavou, Czech Republic
}

Erratum to: Apidologie (2013) 44:404-418

DOI: $10.1007 / \mathbf{s} 13592-012-0190-5$

In the original article the subspecies of honeybee is mentioned incorrectly as Apis mellifera mellifera.

The correct term for these honeybees from a colony of subspecies is Apis mellifera carnica throughout the article.

Everything else in the paper remains correct.

The online version of the original article can be found at http://dx.doi.org/10.1007/s13592-012-0190-5.

Corresponding author: T. Erban, arachnid@centrum.cz Manuscript editor: Klaus Hartfelder 